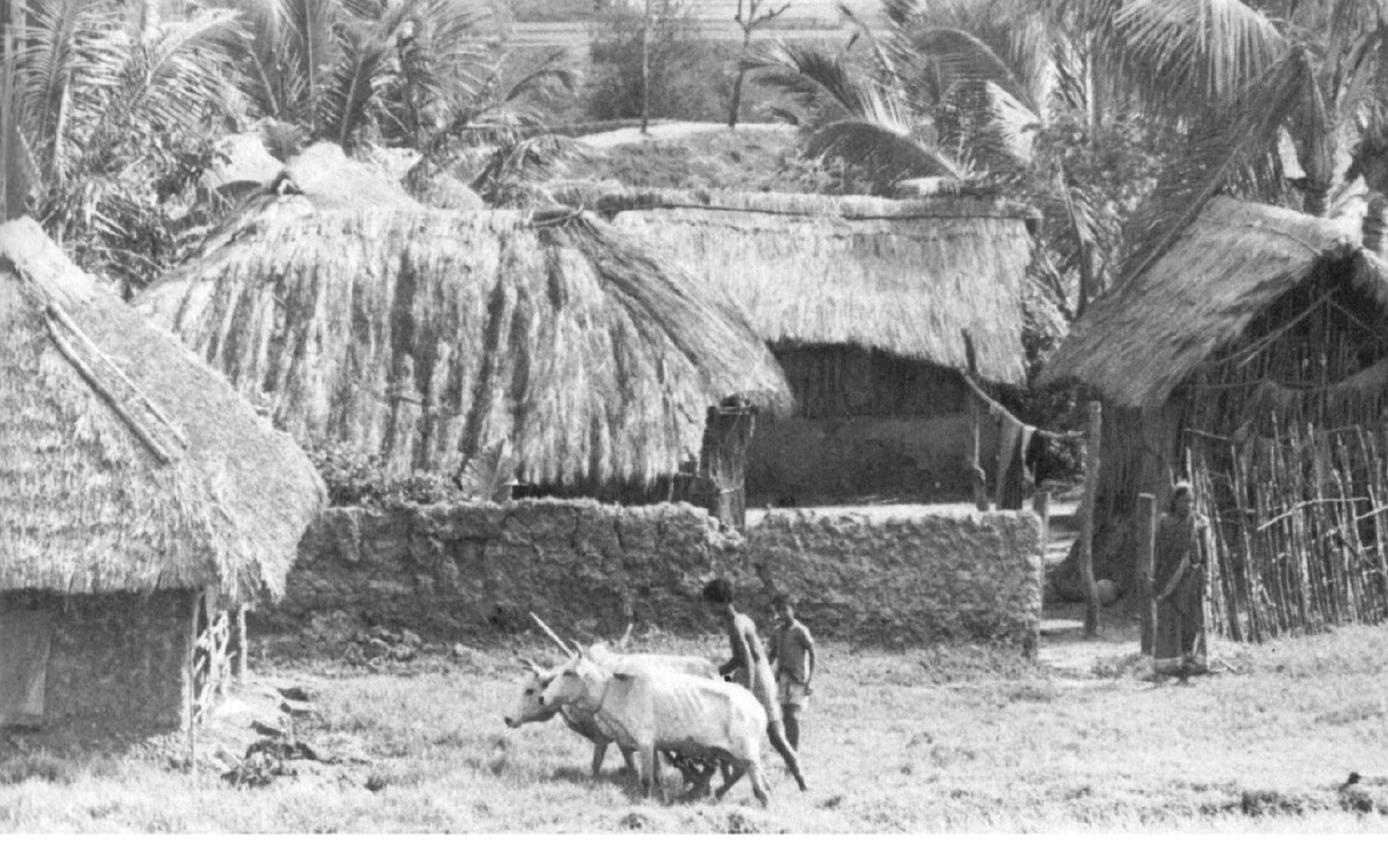

\title{
Problem Tiger in the Sundarbans
}

\section{John Seidensticker, R. K. Lahiri, K. C. Das, and Anne Wright}

In August 1974 a young male tiger moved into a populated area in the Sundarbans, the delta of the Ganges, and killed one woman and a number of livestock. Rather than destroy the animal the Forest Directorate decided to capture it, using immobilising drugs, and release it in the Sundarbans Tiger Reserve. This was successfully done, but less than a week later it was found dead from wounds evidently inflicted by another tiger. The authors discuss the implications of the incident, the publicity it attracted, and the changes in public attitudes.

In the early morning of August 2nd, 1974, a tiger was reported to have killed a woman near the village of Jharkhali, $70 \mathrm{~km}$. south-east of Calcutta, in a reclaimed part of the Sundarbans in the Ganges delta. The tiger was sighted repeatedly over the next few days, and people were very alarmed. On August 7 th, the State Wildlife Officer, R. K. Lahiri, arrived by motor launch to investigate and report to the West Bengal Forest Directorate, the authority responsible under the 1972 Wild Life Protection Act.

The tiger was roaming in a densely populated region of a large delta island, a mosaic of paddy fields, villages and a large central mangrove marsh used as a fishery. The area had been part of reserve forest lands until about 1955, when it was reassigned for the resettlement of refugees. The remaining reserve forests on the southern end of the island were about $3 \mathrm{~km}$. from the villages where the tiger was observed. A narrow belt of mangroves along the Matla River on the west side and the central fishery area provided the tiger with 
shelter and cover but no large mammalian prey. Further south, in the reserve forests and in the tiger reserve, axis deer Axis axis and wild pigs Sus scrofa occur in good numbers.

The body of the dead woman had not been eaten. Lahiri ${ }^{9}$ reported that there was a goat shed less than a metre from where she had been sitting, and, as the incident occurred in the early hours of the morning, 'the circumstances suggest, that the woman may have fallen victim by accident'. The tiger had also killed dogs, cattle and a chicken, but in most cases had not been able to drag away or even feed on its kills, being driven away by the shouting and disturbance people created after each kill. The tiger did not defend its kills, nor did it return to the sites.

The Sundarbans forests are one of the very few remaining places where tigers still occasionally kill people for food, ${ }^{13}$ and vivid accounts enrich many old shikar books. The reasons have been a continuing subject of speculation and there have been investigations recently in Bangladesh by Hendrichs ${ }^{7}$ and in India by Chaudhuri and Chakrabarti. ${ }^{5}$

Occasionally, large and potentially dangerous mammals become isolated or stranded in unsuitable or populated areas from which they must be removed. In the past there has been little alternative but to destroy them. Now, however, effective chemical restraint procedures and equipment make it possible to capture the animal, transport it and release it in a suitable area. Although widely used in Africa and North America, ${ }^{17}$ this management technique had never been used on free-roaming large mammals on the Indian subcontinent.

After this particular incident extreme pressure was brought to bear on the responsible officials to destroy the tiger immediately. But, as the evidence indicated that it was neither a man-eater nor an incorrigible man-killer, it was protected under the 1972 Wild Life Protection Act. The Forest Directorate decided to capture and translocate it by darting, using methods worked out during a tiger ecology study in the Nepal terai by Seidensticker et al. ${ }^{15}$ Once immobilised the tiger could be examined and, if physically fit, moved to the Sundarbans Tiger Reserve. If not fit, it could be kept and treated in captivity under controlled conditions until cured, and then released back into the wild. Seidensticker was invited to assist and flew down from Nepal.

THE TIGER was darted in the mangroves between the dike and the tong

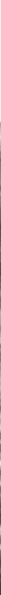




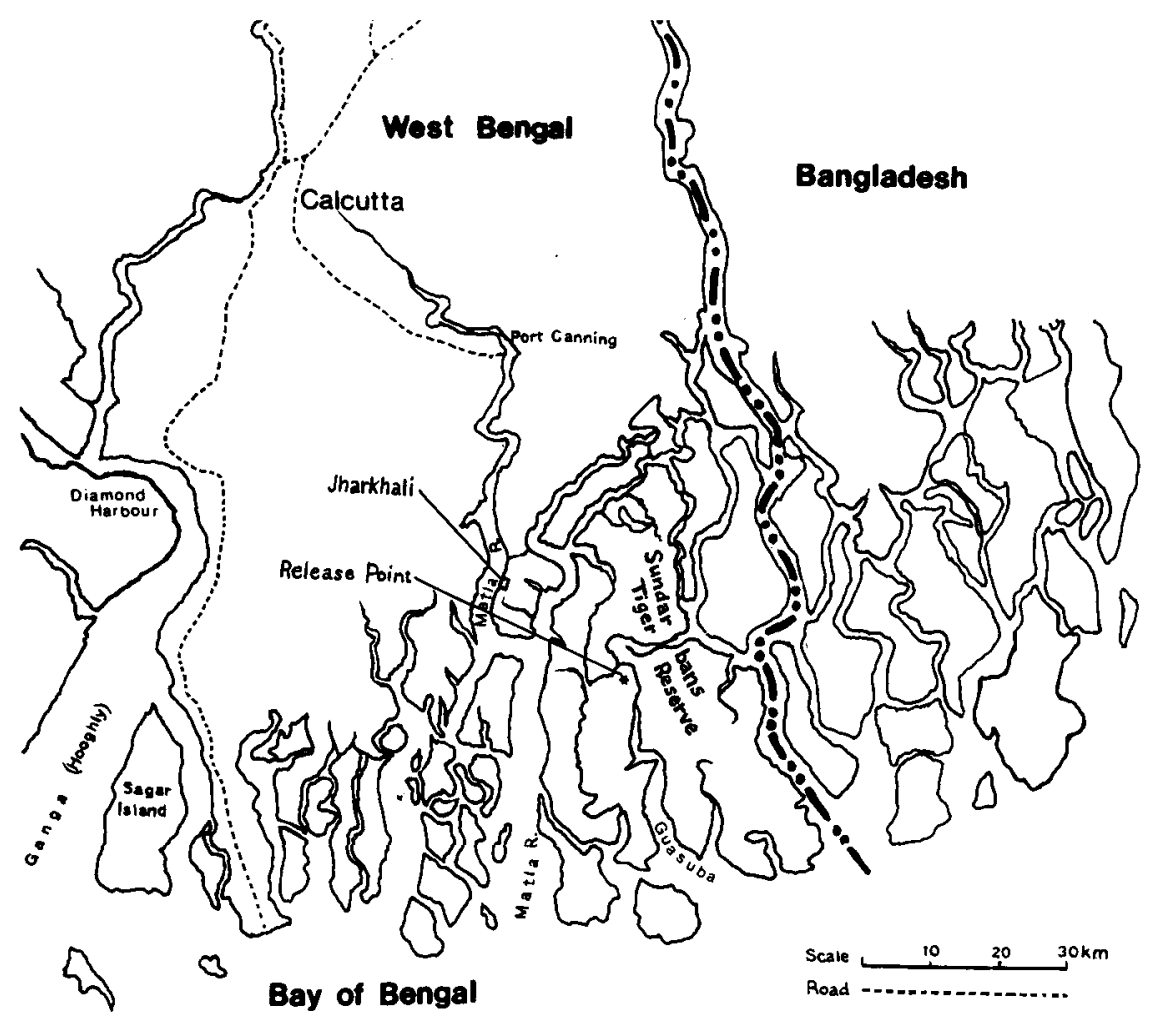

Capture and Release

K. C. Das and R. K. Lahiri were joint directors of logistics and field operations for the Forest Directorate mission. Two motor launches were used for transport and communications with Calcutta and Port Canning, five hours away.

The tiger's approximate location was soon established. The reclaimed populated area is maintained with a system of bunds (dikes) which provide people and livestock with a trail network to move through the mangrove marsh and paddy fields. An intense monsoon storm and unusually high tides had breached the bunds in many places, and the region was mostly inundated by the daily $18-20 \mathrm{ft}$. tides. ${ }^{6}$ However, pugmarks made early in the morning of the 17th led to one of the dry thorn-covered hummocks in the central marsh, near the spot where a cow had reportedly been killed four days before, and where next day we found a cow's scapula. We decided to try to hold the tiger here away from the villages while the fishery owners repaired the dikes so that the water level could be lowered. Meanwhile we worked on developing the conditions needed to dart the tiger successfully.

Over the next nine days, we tied three bullocks on the hummock as baits, secured with nylon rope to prevent the tiger from dragging them away. $\mathrm{He}$ killed and ate the first two, and also two dogs that came to feed on the carcases. A bullock that wandered into the area on the night of the 19th was attacked but escaped along the narrow bund.

After four days of observations from the tong, a boat with a secure hide for observation and darting was moved into position less than 50 feet from the baiting site. It was clear that the tiger would only come to the baiting site 


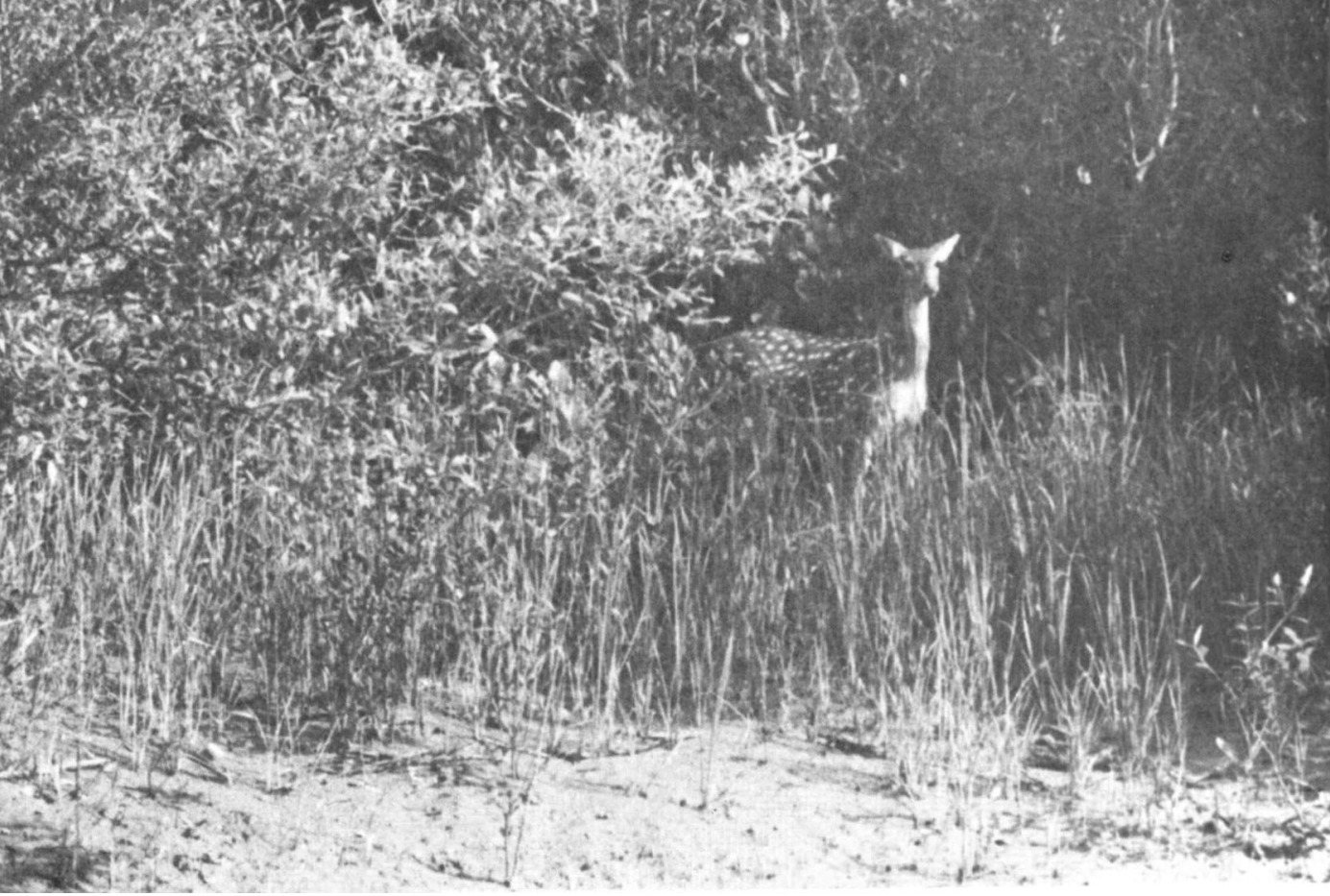

AXIS DEER near the tiger's release point

in the dark, making a night darting necessary, so we built a 15 -foot-high machan 100 feet away for a spotlight.

The tiger then managed to pull the remains of the second bullock free and drag it into the mangrove scrub out of sight. So the third bait was tied. The water level had been lowered, conditions were right for darting, but the tiger returned to feed on the hidden remains of the second bullock. He did not come to the third bait until just after midnight on the 26th, when he rushed and killed it. We darted him ten minutes later and found him immobilised 60 metres away on a mud bank in the mangroves.

He was a young male not fully grown. We examined him thoroughly and found no physical defects, and, as in the previous days that we had been observing him he had appeared to be behaving as normally as could be expected, there was no apparent reason to keep him in captivity. He was therefore put into a zoo transfer cage and moved to the launch, and by daylight we were already on our way to the release site in the core area of the tiger reserve. After about two hours the effects of the drug wore off and he could push against the bars. We took great care to avoid any undue disturbance during the journey.

At the release site, the cage was carefully moved ashore, turned on its side, and the door pulled open with a rope from the launch, thus avoiding the need to immobilise the animal again. After a few minutes the tiger walked out into the deep mud and went off into the thick mangroves behind the cage.

The follow-up of the operation could only be done by periodically checking the area, as radio-location was not permitted in the tiger reserve. On the afternoon of the 28th the tiger was seen back in the transfer cage, but was gone by morning. On hearing this the Chief Conservator, Mr Roy Choud- 


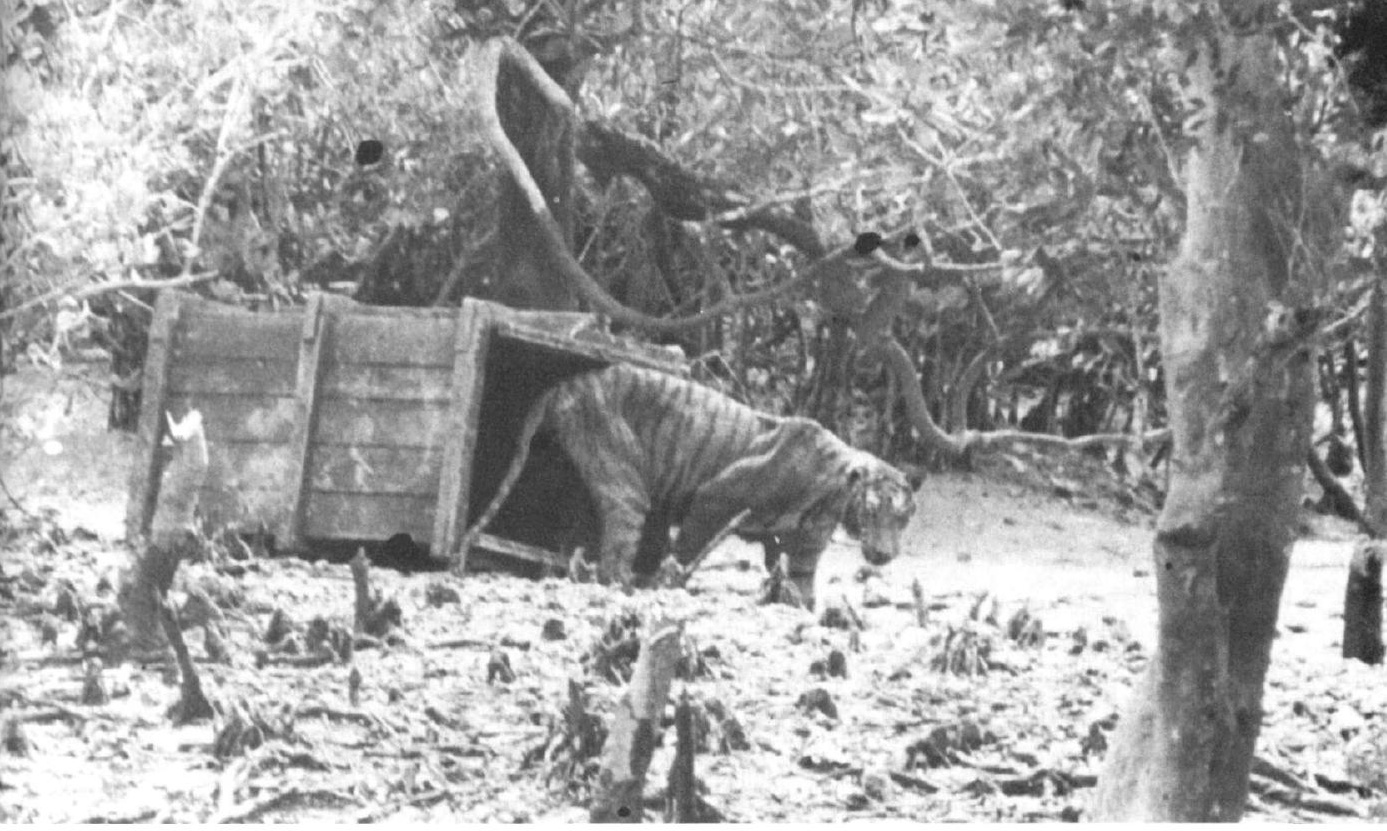

Leaving the transfer cage in the mangroves

hury, asked Lahiri, Das and Seidensticker to return to the site, where we arrived at midday on September 1st. We found the tiger dead in the mangroves, 20 metres from the transfer cage. There were numerous tiger tracks around both the cage and the carcase, and the freshest tracks, which had been made in the few hours before the last high tide, and many of the older ones were larger than those of the dead tiger. The carcase was already badly decomposed. The right side and abdomen had numerous maggot-infested puncture wounds, the thoracic cavity had puncture wounds, and there were multiple puncture wounds in the hips and right shoulder. Only the extremities had been fed on by scavengers. A small monitor Varanus salvator ran away as we approached. No other large predators occur in this region, and we could only conclude that this tiger had died of injuries resulting from an encounter with another tiger.

Observations of tigers over the years have provided only the most preliminary picture of the social organisation and land-tenure system of this big cat. Schaller's work in Kanha National Park ${ }^{13}$ greatly advanced our understanding, but the ability to predict requirements can only come from intensive studies using modern field techniques such as radio telemetry.

Scattered through the old shikar literature are reports of tigers fighting and even killing one another, ${ }^{1,2,4}$ but without any critical data such as the exact conditions and the social role of the individuals involved. Fighting has occurred also in confined situations such as zoos and wild animal parks ${ }^{12,16}$ and is a factor that has to be considered in captive management. But Schaller's work in Kanha and McDougal and Seidensticker's observations in Nepal ${ }^{10}$ showed very little overt aggressive interaction. In these free-ranging tiger populations, where individuals were presumably familiar with one another, fighting was unusual; avoidance and restraint were the rule.

The outcome of this translocation was unfortunate, but the Forest Directorate's monitoring effort turned it into a learning experience. Obviously we 
are a long way from understanding the complexities of injecting an 'outsider' into an existing social structure, and under present conditions this ignorance is critical.

As long as people and tigers live side by side, tigers will occasionally wander into or become trapped in areas from which they will have to be removed. One alternative is to capture and move them to a zoo, or some similar confined situation. This is perhaps a notch above killing the animal outright, but with the large number of tigers already in captivity, the recent successes in captive breeding, and all the evidence indicating the continued decline of tigers in the wild, we did not consider this a logical or even legitimate approach.

The intensive management required to ensure the tiger's survival in the wild will involve manipulating the environment to enhance living conditions as well as applying precise techniques to the tiger population directly. We can anticipate the problems of maintaining genetic variability in isolated populations of what was once a widely distributed species ${ }^{3}$ and, from our knowledge of population processes in other solitary big cats ${ }^{14}$ we can also anticipate difficulties in maintaining breeding populations in the small isolated sanctuaries which are the basis of the current tiger preservation programme. ${ }^{8,11}$

Our lack of understanding of these fine-tuned behavioural factors and mechanisms hampers our efforts to preserve these great cats, and action must await the results of carefully planned long-term research. Meanwhile there will continue to be problem tigers, and recent events in Orissa and Assam, where problem tigers have been shot, point to the urgent need for guidelines if such tigers are to be preserved in the wild. Suitable release sites with good natural prey populations will have to be identified, often perhaps in forest reserves rather than in existing tiger sanctuaries. Managers and research workers must co-operate, and an infrastructure is needed for developing plans and for reviewing and incorporating new information, as it becomes available, into all field operations.

The publicity achieved by this Sundarbans tiger incident was considerable and the public attitudes interesting. The fact that this tiger killed a woman was immediately reported in the press, and the debate about the tiger's fate, the capture, the translocation, the tiger's death and the ensuing discussions were all fully reported. Our file from Calcutta and New Delhi English-language newspapers alone includes 81 articles. For over six weeks the operation was constantly before the public.

Unfortunately no detailed survey of public attitude was made before and after the operation, but it seemed clear from the reporting that shifts were occurring. At the beginning the pressure for the tiger's destruction was intense; by the end, the death of 'Sundar' seemed to be lamented, and, of course, there was much debate on how the operation should have been conducted.

The publicity was unplanned and we tried to avoid it; it added considerable pressure to a difficult undertaking. But for the larger conservation perspective it was important. At first the arguments raised were the old anti-predator ones, but at the end, the non-politically motivated accounts seemed to be moving toward a position in line with today's environmental approach, with a growing realisation that the fate of this great cat truly lies in man's hands and in man's ability to provide for its ecological needs in a man-dominated environment. Ultimately, the tiger's survival in the wild depends on public 
awareness and attitudes towards the larger issue, that of man learning to come to grips with the constraints of the land and developing a realistic rapport.

\section{Acknowledgments}

Many individuals, on short notice, invested considerable time and effort in making the arrangements necessary for this operation. Special credit in West Bengal is due the Chief Minister, S. S. Ray, the Chief Secretary, B. R. Gupta, the Secretary of Forests, T. B. Singh, and the Chief Conservator of Forests, K. C. Roy Choudhury. The Inspector General of Forests, K. L. Lahiri, the United States Mission to India, the Foreign and Home Ministries of His Majesty's Government of Nepal, and the United States Mission to Nepal, all offered support in obtaining the immobilising equipment and arranging for permits and customs clearance. The West Bengal Forest Directorate provided operational costs. The World Wildlife Fund - India provided for Seidensticker's travel from Kathmandu. The Smithsonian Institution loaned the necessary immobilising equipment. Personnel of the 24-Paraganas Forest Division, the crews of the launches Banashri and Barabala, and the people of the Jharkhali area provided indispensable assistance in the field. The Director, Calcutta Zoo, loaned a transfer cage.

\section{References}

1. BAKER, E. 1886. Sport in Bengal: how, when, and where to seek it. London.

2. BRANDER, A. 1923. Wild Animals in Central India. London.

3. BUECHNER, H. and MARSHALL, D. 1975. Threatened ungulates of North America. In Proc. Symp. on Endangered and Threatened Species in North America. Wild Canid Survival and Research Center, Wolf Sanctuary, St. Louis (in press).

4. BURTON, R. 1933. The Book of the Tiger. London.

5. CHAUDHURI, A. and CHAKRABARTI, K. 1972. Observations on Tigers: wildlife biology of the Sundarbans forests. Divisional Forest Office, 24-Parganas Division, Calcutta. 18 pp. (mimeo).

6. FOSBERG, F.R. 1971. Mangroves and tidal waves. Biol. Cons. 49: 38-39.

7. HENDRICHS, H. 1972. Project 669 tiger: study of man-eating problems in the Sundarbans. In World Wildlife Yearbook 1971-72, 109-115. Morges, Switzerland.

8. INDIAN BOARD FOR WILDLIFE (GOI). 1972. Project Tiger. New Delhi.

9. LAHIRI, R.K. 1974. Report on the Investigation of Depredation Caused by Tiger in Parbatirpur Mouza, under Basanti Police Station. West Bengal Forest Directorate. 5 pp. (typed).

10. MCDOUGAL, C. and SEIDENSTICKER, J. 1976. Predatory behavior of tigers (Panthera tigris tigris L.): ecological and sociological aspects. $120 \mathrm{pp}$. (typed $\mathrm{ms}$.).

11. MOUNTFORT, G. 1973. Tigers. Newton Abbot, Devon.

12. SANKHALA, K. 1967. Breeding behavior of the tiger, Panthera tigris, in Rajasthan. Inter. Zoo Yb., 7: 133-147.

13. SCHALLER, G. 1967. The Deer and the Tiger: a study of wildlife in India. Chicago.

14. SEIDENSTICKER, J., HORNOCKER, M., WILES, W., and MESSICK, J. 1973. Mountain lion social organization in the Idaho Primitive Area. Wildl. Monog., 35: 1-60.

15. SEIDENSTICKER, J., TAMANG, K., and GRAY, C. 1974. The use of CI-744 to immobilize free-ranging tigers and leopards. J. Zoo. Animal Med., 5(4): 22-25.

16. SHOREY, D. and EATON, R. 1974. Management and behavior of Bengal tigers under semi-natural conditions. In R. Eaton, ed., The World's Cats, Volume II: Biology, Behavior and Management of Reproduction, 204-221. Feline Research Group, Woodland Park Zoo, Seattle.

17. YOUNG, E. (ed.). 1973. The Capture and Care of Wild Animals. Capetown and Pretoria.

Dr Seidensticker is Research Associate, National Zoological Park, Smithsonian Institution, Washington, D.C. 20009, USA; Mr Lahiri is State Wildlife Officer, West Bengal Forest Directorate, P. 16 India Exchange Place Ext., New CIT Building 12-700012, Calcutta, India; Mr Das was Field Director, Sundarbans Tiger Reserve, West Bengal Forest Directorate, P. 16 India Exchange Place Ext., New CIT Building 12-700012, Calcutta, India; Mrs Wright is a Trustee, World Wildlife Fund - India, and Member, Indian Board for Wildlife. 